\title{
Strategies Needed to Ensure Higher Immunization Rates in the Americas
}

\section{To the Editors:}

In their MEDICC Review Perspective, Galindo-Santana and colleagues highlight the challenges presented by anti-vaccination groups, stressing that immunization is an essential cost-effective preventive measure that promotes population health.[1] In 2019, WHO identified vaccine hesitancy, fragile and vulnerable settings and weak primary health care as 3 of 10 main global health threats. Close attention to these threats can detect potential areas of missed opportunities for immunization across populations and mitigate risk of preventable diseases.

In recent decades, expanding immunization coverage to reduce child morbidity and mortality from preventable communicable diseases has been an international priority: WHO developed the Expanded Programme on Immunization in 1974, established the Strategic Advisory Group of Experts on Immunization in 1999, and accepted the Global Vaccine Action Plan 2011-2020 in 2012. Regional efforts in the Americas have successfully eliminated polio, rubella and neonatal tetanus, aiming to eliminate hepatitis $B$ by 2020.[2] These goals require robust coordination efforts to strengthen global health workforce capacity, support educational outreach about adherence to vaccination schedules and expand service delivery to all communities. With recent resurgence of vaccine-preventable diseases like measles, however, nations must identify gaps and challenges in immunization programs and explore opportunities to maintain high immunization coverage.

To strengthen immunization efforts in the Americas, we propose that leaders in ministries of health prioritize three actions. First, community-based research using quantitative and qualitative approaches can examine the determinants of health that influence community understanding of and adherence to recommended vaccination schedules. Second, capacity building for nurses and health promoters can offer accurate, up-to-date vaccination recommendations and reinforce competencies. Third, primary health care centers can promote holistic health through the One Health concept, which describes the interconnectedness of human, animal, and environmental health, while dispelling myths and fostering provider-patient rapport and acceptance of evidence-based vaccination schedules.

Regional action for widespread adoption of evidence-based vaccination schedules is essential to safeguard population health. By prioritizing community-based research, health capacity building and the One Health concept, nations can accelerate progress to achieving high immunization coverage through Sustainable Development Goal targets 3.8 and 3.b. - $/$ -

1. Galindo-Santana BM, Cruz-Rodríguez E, López-Ambrón L. A Cuban perspective on the antivaccination movement. MEDICC Rev. 2019 Oct;21(4):64-9.

2. Pan American Health Organization. Basic indicators 2019: Health trends in the Americas [Internet]. Washington, D.C.: Pan American Health Organization; 2019 [cited 2020 Jul 5]. Available at: http://iris.paho.org/xmlui/han dle/123456789/51543

3. World Health Organization [Internet]. Geneva: World Health Organization; c2020. SDG 3: Ensure healthy lives and promote wellbeing for all at all ages. The goals within a goal: Health targets for SDG 3; [cited 2020 Jul 5]; [about 1 screen]. Available at: https://www.who.int/sdg/targets/en/

Bienvenido A. Veras-Estévez MD MPH (bienvenido.veras@ucateci .edu.do), Faculty of Health Sciences, Catholic University of the Cibao, La Vega, Dominican Republic.

Helena J. Chapman MD MPH PhD, Milken Institute School of Public Health, George Washington University, Washington, D.C., USA. 